\title{
APLIKASI ALAT MUSIK GAMELAN JAWA PADA PERANGKAT ANDROID
}

\author{
Putra Adi Sumirat \\ Jurusan Teknik Elektro Fakultas Teknik Universitas Muhammadiyah Surakarta \\ J1. A. Yani Tromol Pos 1 Pabelan Kartasura, Surakarta \\ E-mail: putrasciencebowl@gmail.com
}

\begin{abstract}
ABSTRAKSI
Gamelan Jawa merupakan suatu peninggalan kebudayaan Indonesia yang semakin tergeser oleh masukkya kebudayaan barat yang mempengaruhi cara bermusik masyarakat Indonesia. Maka dari itu perlu dibuat Gamelan Jawa dalam bentuk yang baru agar kesenian ini dapat dilestarikan dengan cara yang modern. Salah satunya adalah, dengan membuat aplikasi Gamelan Jawa pada perangkat smartphone berbasis android.

Metode penelitian yang dilakukan pertama adalah merekam suara dan mengambil foto Gamelan, kemudian suara diolah dengan software Audacity untuk memotong setiap notasi Gamelan. Tahap selanjutnya adalah mendesain sistem dengan software Eclipse yang sudah terpasang ADT, kemudian sistem diuji dengan SDK. Dan untuk desain gambar Gamelan menggunakan software Adobe Potoshop serta untuk mengedit audio menggunakan software Audacity.

Aplikasi Gamelan Jawa berbasis android ini memiliki tujuh pasang Gamelan laras slendro dan pelog, serta satu buah kendang siter. sistem dalam aplikasi ini dapat menghasilkan suara Gamelan yang diinginkan jika ikon pada aplikasi tersebut disentuh. Perangkat aplikasi ini juga dapat dimainkan dengan dua jari yang memungkinkan dua suara yang berbeda pada saat yang bersamaan.
\end{abstract}

Kata Kunci : Sistem Aplikasi, Berbasis Android, Gamelan Jawa

\section{PENDAHULUAN}

Gamelan Jawa merupakan alat musik kebudayaan Indonesia peninggalan nenek moyang yang tidak diketahui secara pasti kapan dan bagaimana terciptanya. Gamelan biasa dimainkan sebagai sebuah pertunjukan seperti Wayang kulit dan Ketoprak (Haryono 2007).

Masyarakat Jawa, orchestra musik gamelan biasanya disebut "Karawitan" yang berarti rumit, halus, kecil. Kesenian Jawa ini pada saat ini masih ditampilkan pada acaraacara resmi seperti pernikahan, syukuran, dan lain-lain (Supanggah, 2002). Namun kian lama kesenian ini makin tergusur seiring dengan masuknya kebudayaan barat yang mempengaruhi cara bermusik masyarakat Indonesia. Maka dari itu perlu dibuat Gamelan Jawa dalam bentuk yang baru agar masyarakat Indonesia tertarik pada kesenian Jawa yang mulai dilupakan ini, dan salah satunya adalah dengan membuat aplikasi alat musik Gamelan jawa yang dapat dimainkan pada smartphone berbasis Android.
Android merupakan sistem operasi mobile bersifat open source yang dikembangkan oleh Google, dan memiliki tool khusus yang dapat membantu pengembang Android untuk membuat aplikasinya sendiri (Widianto, 2011).

Sistem Band Musik Digital Pada Portable PC Berbasiskan Web". Dari penelitian tersebut penulis meneliti sebuah sistem yang melakukan simulasi band secara digitaldengan menggunakan media web sebagai aksesnya (Isa Yahya).

Belajar Gamelan Jawa Menggunakan Platform iOS" penulis tersebut menjelaskan bahwa perlu dilakukan pengimplementasian pada teknologi multimedia layar sentuh pada iPhone, iod Touch, dan iPad. Bahasa pemrograman yang digunakan adalah objective-C (Andhika Kurniawanto).

Kowpling Studio, kumpulan seniman dari Yogyakarta telah membuat aplikasi Gamelan DJ. Aplikasi ini memiliki satu set peralatan DJ, Gamelan Saron Pelog dan disertai dua 
lagu daerah yaitu Gundul-gundul Pacul dan Suwe Ora Jamu.

Gamelan Toetoel, merupakan aplikasi yang memiliki tujuh perangkat Gamelan Jawa laras slendro dan pelog, yaitu Demung, Saron, Peking, Slenthem, Kempul, Bonang Barung, dan Bonang Panerus.

\section{METODE PENELITIAN}

Perekaman suara dan pengambilan gambar Gamelan jawa di rumah milik Bapak Yoko, Bakalan, Tanduk, Ampel, Boyolali. Serta wawancara para ahli penabuh Gamelan, Bapak Suwondo, Bapak Wiryo dan Bapak Gunarto, Gatak, Tanduk, Ampel, Boyolali.

\section{a. Analisa Kebutuhan}

Analisa kebutuhan meliputi kebutuhan software dan hardware.

a) Analisis kebutuhan software

1. Sistem Operasi Windows 7 - 32 bit.

2. Eclipse 3.8

3. Android SDK (Software Development Kit) 4.2.2 Jelly Bean

4. ADT (Android Developer Tools) 21.1.0.2013

5. JDK (Java Development Kit) 1.7.0_21

6. JRE (Java Runtime Environment) $\overline{7}$

7. Adobe Photoshop CS 5

8. Audacity 2.0.3

b) Analisis kebutuhan hardware

1. Netbook Acer Aspire One 722 dengan spesifikasi:
a. CPU AMD Dual Core $1 \mathrm{GHz}$
b. RAM 2 GB
c. Hardisk $320 \mathrm{~GB}$
d. VGA AMD Radeon HD 6250 Graphics 879 MB

2. Smartphone Sony Xperia E dengan spesifikasi:
a. Sistem Operasi Android 4.1 Jelly Bean
b. CPU Single Core $1 \mathrm{GHz}$ Cortex A5
c. RAM 512 MB; Hardisk 2 GB
d. Kamera 3.15 MP

\subsection{Desain Sistem}

Desain sistem menjelaskan tentang bagaimana user dapat menggunakan aplikasi ini. Contohnya adalah sebagai berikut:

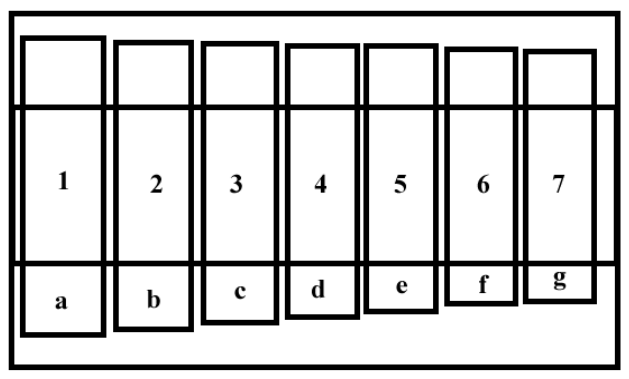

Gambar 1. Desain Saron Pelog

Gambar 1 merupakan desain Saron Pelog. Cara memainkannya adalah ketika bagian angka 1-7 (sesuai tinggi rendahnya nada) disentuh, maka akan berbunyi suara yang diinginkan. Dan pada bagian huruf a-g, merupakan bagian untuk menghentikan suara yang ditimbulkan pada masing-masing bagian.

2.1 Pemrosesan Sinyal Suara

Pemrosesan suara dilakukan dengan bantuan software Audacity 2.0.3 untuk pemotongan setiap notasi suara yang direkam dengan microphone dari smartphone Sony Xperia E. Proses yang pertama adalah perekaman suara setiap perangkat Gamelan, kemudian hasil dari rekaman suara tersebut diolah pada software Audacity untuk pemotongan setiap notasi perangkat gamelan, serta mengkonversi format file suara dari *.wav menjadi *.ogg untuk mengkompresi ukuran file suara, dan tahap akhir file suara dimasukkan dalam sistem.

\section{HASIL PENELITIAN DAN ANALISA}

Sistem dan program yang telah berjalan menjadi sebuah hasil dan tujuan akhir dari pembuatan aplikasi Gamelan Jawa berbasis androi. Sistem yang telah diimplementasikan kemudian dilakukan tahap perawatan, hal tersebut dimaksudkan agar sistem dapat terus berjalan dengan baik sesuai dengan fungsinya dan jika diperlukan sistem dapat dikembangkan sesuai dengan teknologi yang terus maju dan berkembang. 


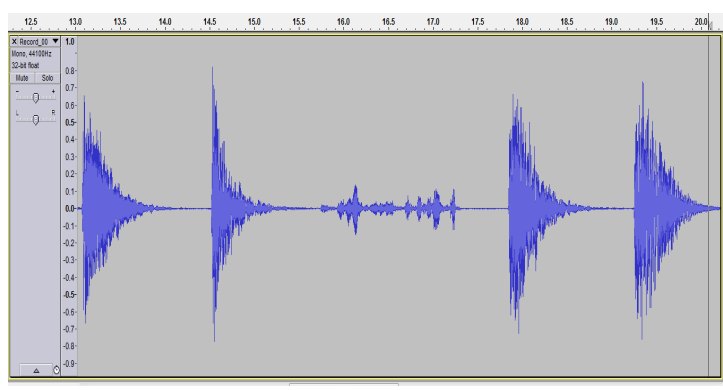

Gambar2.Sinyal suara sebelum dipotong

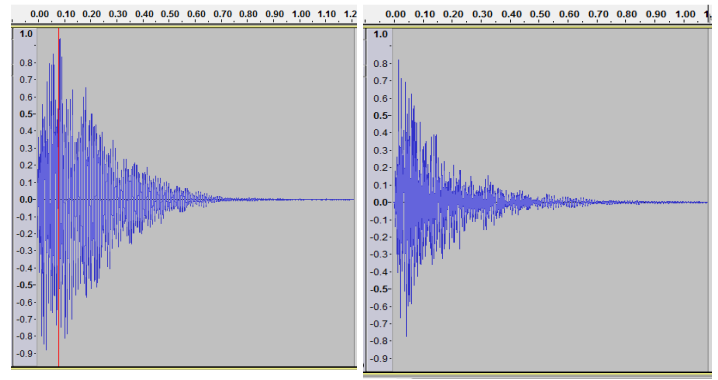

Gambar 3.Sinyal suara setelah dipotong

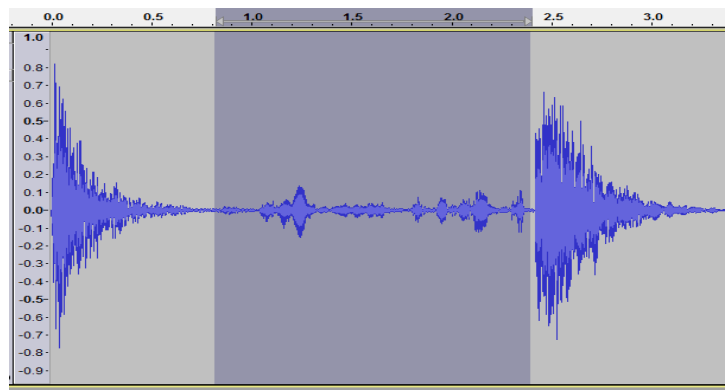

Gambar 4.Sinyal suara yang tidak terpakai

1. Analisa Pemrosesan Sinyal Suara

Analisa pemrosesan sinyal suara dilakukan menggunakan software Audacity 2.0.3 yang berfungsi untuk pemotongan suara setiap notasi Gamelan, serta untuk mengubah format audio dari *.wav menjadi *.ogg, agar ukuran audio menjadi lebih kecil. Berikut ini adalah contoh gelombang suara yang belum dipotong pada perekaman suara Kendang Siter:

Pada gambar 2, sinyal suara Kendang Siter akan dipotong pada setiap ketukan gamelan. Sedangkan pada gambar 3, merupakan dua bentuk sinyal yang hampir sama namun dengan suara dan frekuensi yang berbeda. Kemudian juga terdapat sinyal suara yang bukan merupakan suara gamelan, yang ditunjukkan pada gambar 4, bagian yang diblok merupakan suara yang bukan suara gamelan, sedangkan pada bagian gambar yang tidak diblok, merupakan gambar dari sinyal suara gamelan yaitu dengan frekuensi yang lebih tinggi. Bagian dengan gelombang suara yang lebih tinggi inilah yang akan dipotong untuk kemudian format suara akan diubah dari format *.wav menjadi *.ogg.

\section{Analisa Sistem}

Analisa sistem ini hanya diambil beberapa alat saja dari seluruh perangkat Gamelan yang penulis buat. Hal tersebut dikarenakan semua program hampir sama dan hanya berbeda pada pemberian nama gambar, suara dan pada desain tampilan aplikasi. Namun sebenarnya sebagian besar bahasa pemrograman seluruh perangkat Gamelan Jawa berbasis android ini adalah sama, maka hanya diambil beberapa perangkat Gamelan saja sebagai sampel.

\section{a. Menu Utama}

Menu umum ini terdapat pilihan berbagai alat musik Gamelan yang dapat dimainkan.

Analisis Program :

Source Code Menu Utama dari yang dapat menampilkan Gamelan:

1. $\quad$ Source Code pada menu.xml :

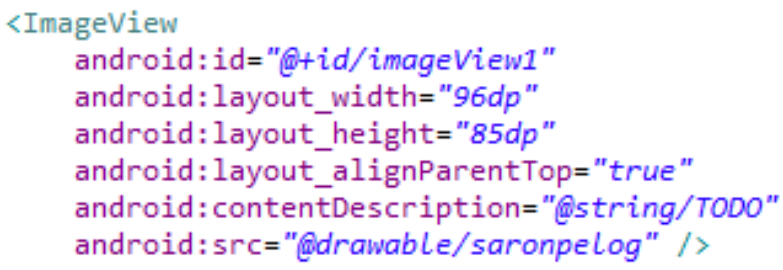

Source Code diatas merupakan perintah untuk menampilkan gambar saronpelog pada menu.xml. Baris 1 merupakan variabel id yang terdapat @+id yang merupakan perintah agar imageViewl dapat secara otomatis terdaftar dalam sistem. Baris 2-3 menjelaskan tentang lebar dan tinggi gambar, baris 4 menjelaskan jika gambar merapat ke atas, baris ke 5 merupakan variabel string, dan baris terakhir menjelaskan tentang gambar yang ditampilkan. 


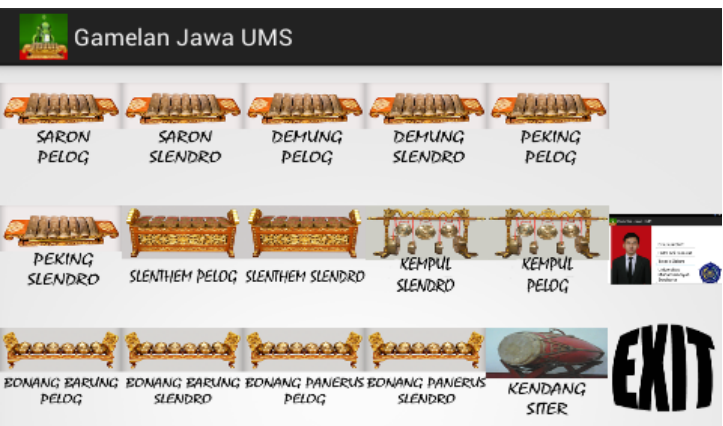

Gambar 5. Tampilan Menu Utama Gamelan android

2. Source Code pada menuActivity.java :

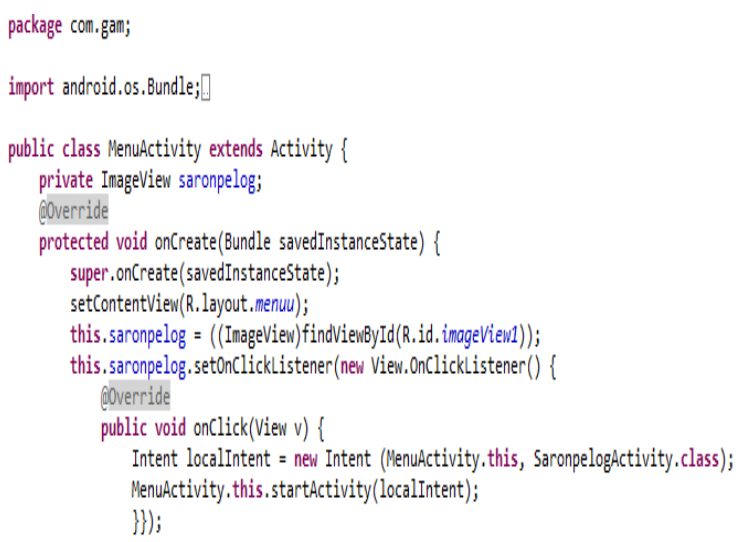

Source Code di atas digunakan untuk memanggil Saronpelog Activity yang berisikan source code untuk menampilkan Saron Pelog. Baris pertama merupakan lokasi package yang berada di com.gam. Baris kedua merupakan daftar perintah yang akan diimport. Sedangkan baris 3-4 merupakan daftar kelas yang terdapat pada pemrograman tersebut. Terdapat 15 (lima belas) kelas yang terdapat dalam permrograman Menu umum tersebut.Baris 5-8 merupakan pernyataan bahwa program menampilkan layout menu, dan baris 9-15 merupakan perintah yang berupa imageViewl yang berisikan ikon pada layout menu jika gambar di-klik maka akan menampilkan SaronpelogActivity.

b. Perangkat Aplikasi Gamelan Jawa

1. Analisa sistem Perangkat Gamelan Jawa yang pertama diambil sampel dari Alat musik metallophones yaitu yang berbentuk bilahan atau lempengan. Dari empat pasanglaras Slendro dan Pelog yang penulis susun yaitu Demung, Saron, Peking dan juga Slenthem, Gamelan Saron Pelog dapat dilihat pada gambar 6 .

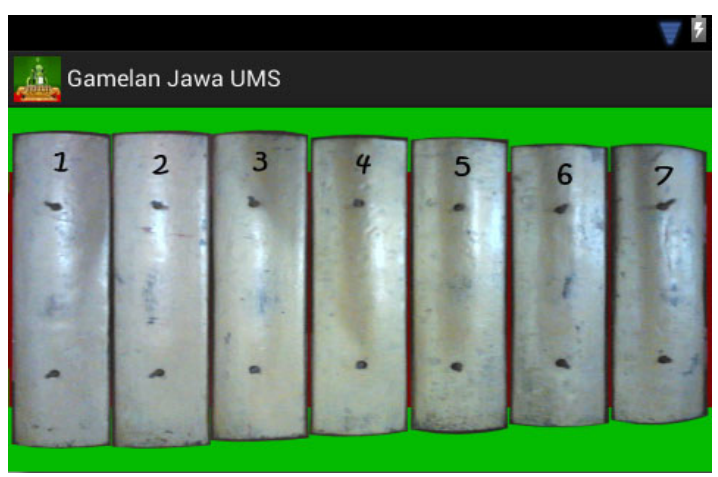

Gambar 6. Tampilan Saron Pelog

Analisis Program:

a. Source Code saronpelog.xml:

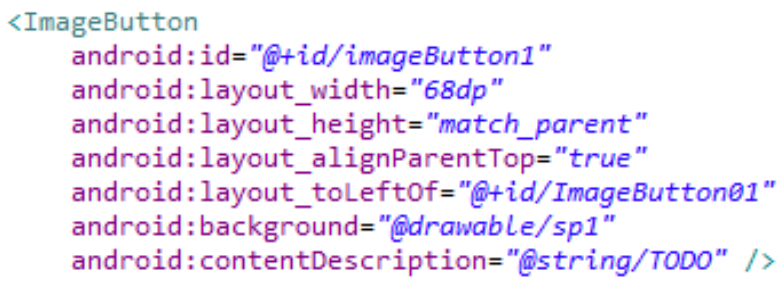

Source Code diatas menjelaskan tentang perintah untuk menampilkan gambar $s p 1$ pada layout yang merupakan bilah pertama pada Saron Pelog.

b. Source Code SaronpelogActivity.java:

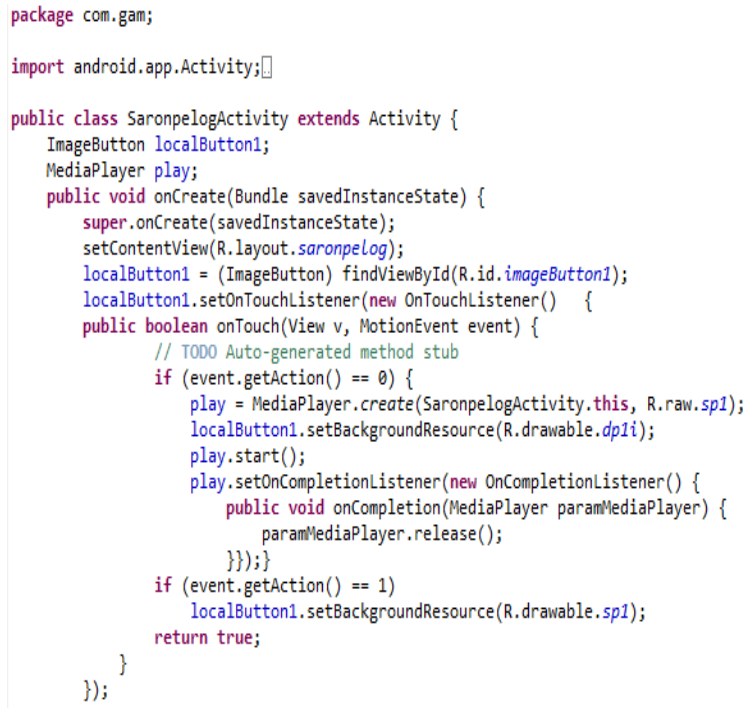

Source Code diatas berisi perintah untuk memutar nada pertamaSaron Pelog. Baris pertama merupakan lokasi package yang berada di foldercom - gam. Baris kedua merupakan daftar perintah yang akan di- 
import. Sedangkan baris 3-5 merupakan daftar kelas yang terdapat pada pemrograman java tersebut. Sebenarnya terdapat 15 (lima belas) kelas yang terdapat dalam pemrograman Saron Pelog tersebut, namun hanya ditampilkan localButton1 dan MediaPlayer sebagai sampel yang akan dijelaskan. Baris 68 merupakan pernyataan bahwa tampilan yang dipakai adalah layout saronpelog. Baris 9-20 merupakan perintahbahwa jika user menyentuh localButton1 yang berisikan gambar spl, maka audio nada pertama yang bernama spl akan diputar, dan juga gambar dari localButtonl akan berganti menjadi $d p l i$ sampai sentuhan dilepaskan. Sedangkan baris 21-25 merupakan pernyataan jika sentuhan pada localButton1 dilepaskan akan berganti menjadi gambar spl yang merupakan gambar localButton 1 semula.

1. Analisa perangkat Gamelan jawa yang berjenis Gong disini akan diambil dua sampel karena tampilan perangkat gamelannya berbeda, yaitu Bonang Barung Pelog yaitu Gong yang diletakkan diatas tali, berisi dari sepuluh hingga empat belas gong dan direntangkan pada bingkai kayu, serta Kempul Pelog yaitu Gong yang digantung pada tiang penggantung.

Analisis program:

1) Source Code bonangbarungpelog.xml

<ImageButton

android: id $=$ "@

android: layout_width="64dp"

android: layout_height $=" 74 \mathrm{dp} "$

android: layout_alignLeft="@+id/imageButton7"

android: layout_alignParentTop="true"

android: layout marginTop="32dp"

android: background=" "edrawable/bngg"

android: contentDescription= "@string/TODO" />

Source Code diatas menyatakan tentang gambar di folder drawable dengan nama bngg yaitu gambar Gong pada Bonang Barung Pelog yang pertama dengan ukuran tinggi 74dp (Density Independent Pixels)dan lebar 64dp, serta berbatas sebelah kiri dan terletak diatas imageButton7. Juga jarak imageButton 1 dengan sisi atas adalah 32dp.

a. Bonang Barung Pelog

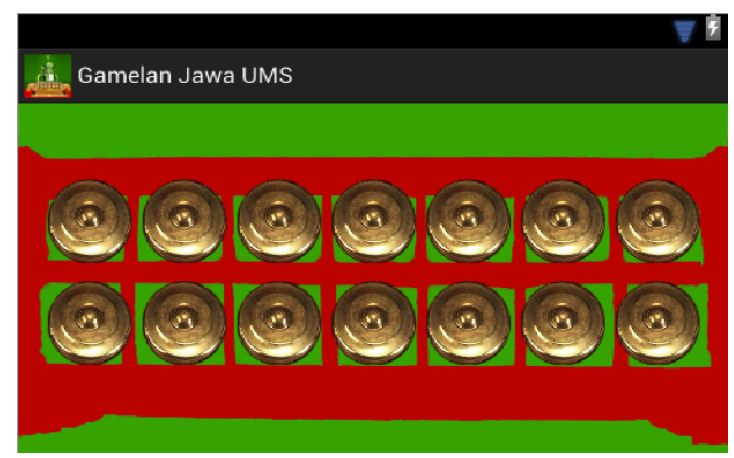

Gambar 7. Tampilan Bonang Barung Pelog

2) SourceCode

BonangbarungpelogActivity.java

package com, gam;

import android. app.Activity; [

public class Bonangaarungpelogactivity extends Activity \{

ImageButton localButtonl;

Medialayer play;

public void onCreate(Bundle savedinstancestate) \{

super, onCreate(savedInstancestate);

setContentView(R. layout, bonangbarungpelog);

localButton $1=($ ImageButton $)$ findViewById(R, id. imageButton1);

localButton1, setOnTouchListener(new OnTouchListener() \{

public boolean onTouch(View v, MotionEvent event) \{

I/ TO00 Auto-generated method stub

if (event, getaction ()$=0)\{$

play = MediaPlayer, create(Bonangbarungpelogactivity, this, R.raw.bbp1a);

localButton1, setBackgroundResource(R, drawable, bng);

play.start();

play, setOnCompletionlistener(new OnCompletionlistener() \{ public void oncompletion(Mediaplayer paranlvediaplayer) \{ paranllediaPlayer, release();

13));\}

if (event, getAction() $=1$ )

localButton1, setBackgroundResource(R,drawable, bngg); return true;

3\});

Source Code diatas berisi perintah untuk memutar nada pertamaBonang Barung Pelog. Baris pertama merupakan lokasi package (paket)yang berada di foldercom.gam. Baris kedua merupakan daftar perintah yang akan di- import. Sedangkan baris 3-5 merupakan daftar kelas yang terdapat pada pemrograman java tersebut. Terdapat 15 (lima belas) kelas yang berada dalam pemrograman Bonang Barung Pelog tersebut. Baris 6-8 merupakan pernyataan bahwa tampilan yang digunakan 
adalah layout bonangbarungpelog. Baris 9-20 merupakan perintah jika user menyentuh localButton 1 maka nada pertama pada Bonang Barung Pelog yang bernama bbpla akan berputar,serta gambar Gong pada imageButton 1 akan berganti menjadi gambar bng sehingga akan tampak seolah-olah bergetar. Pada baris 21-24 merupakan perintah untuk mengembalikan gambar ke bentuk semula yaitu gambar bng ketika sentuhan user dilepaskan. Program ini akan berulang terus menerus jika pengguna menyentuh atau menekan gambar ikon gamelan yang tersedia setiap notasinya pada aplikasi yang tersedia.

a.Kempul Pelog

Analisis program:

1) Source Code kempulpelog.xml

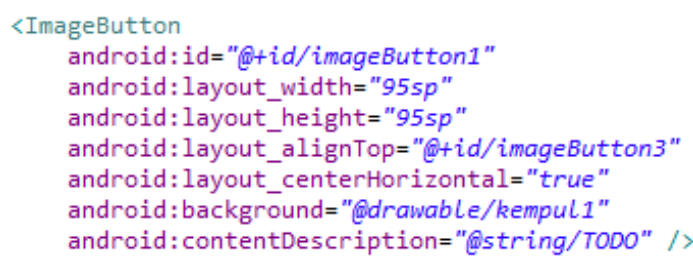

Source Code diatas menampilkan gambar Gong pada Kempul Pelog dengan id:imageButton1 yang bernama kempul1 dengan tinggi 95sp (Scale Independent Pixels) dan lebar $95 \mathrm{sp}$, yang berbatas atas sama dengan imageButton 3 serta terletak tepat di tengah-tengah tampilan.

2) Source Code KempulpelogActivity.java

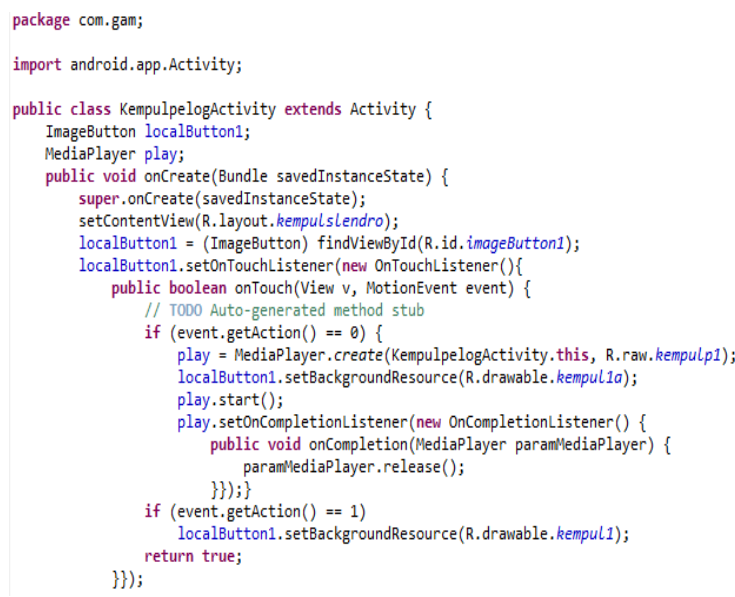

Source Code diatas berisi perintah untuk memutar nada pertamaKempul Pelog. Baris pertama merupakan lokasi package yang berada di com.gam. Baris kedua merupakan daftar perintah yang akan di- import. Sedangkan baris 3-5 merupakan daftar kelas yang terdapat pada pemrograman tersebut. Terdapat 7 (tujuh) kelas yang berada dalam pemrograman Kempul Pelog tersebut. Baris 6-8 merupakan pernyataan bahwa tampilan yang dipakai adalah layout kempulpelog. Baris 9-20 merupakan perintah ketika user menyentuh localButton1 maka file audio yang bernama kempulp1 akan berputar, dan gambar akan berganti menjadi kempulla. Sedangkan pada baris 21-24 merupakan perintah jika sentuhan user dilepaskan maka akan kembali pada gambar kempull yang merupakan gambar pada imageButton1 semula.

A. Sampel analisa sistem yang ketiga adalah perangkat Gamelan yang berjenis Drum yaitu Kendang Siter.

Analisis program:

a.Source Code kendangsiter.xml

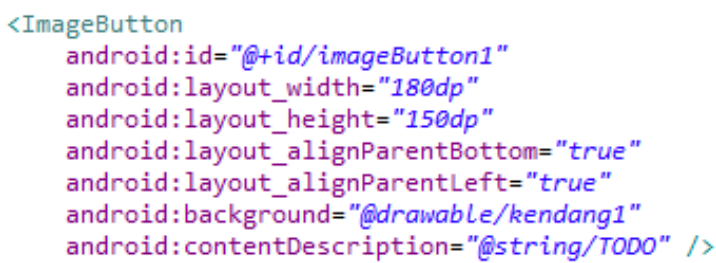

Source Code diatas merupakan perintah untuk menampilkan gambar kendang di sebelah ujung yang kecil pada bagian pinggir. Baris 34 menjelaskan tentang lebar gambar yaitu 180dp dan tinggi 150dp. Pada baris ke 5-6 menjelaskan batas gambar adalah tepat di tengah tampilan dan merapat ke samping kiri.

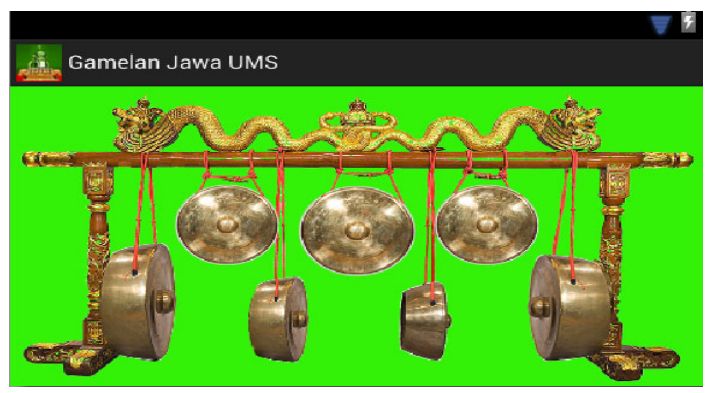

Gambar 8. Tampilan Kempul Pelog 


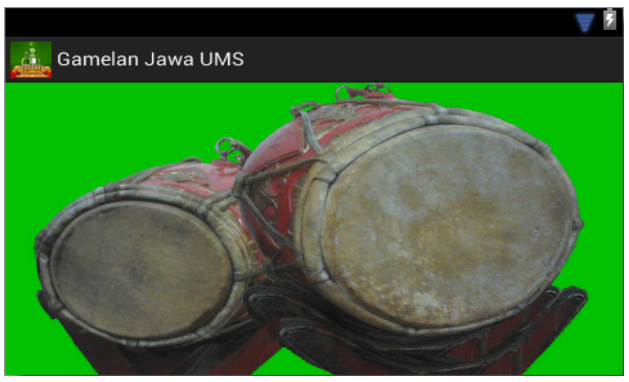

Gambar 9. Tampilan Kendang Siter

b.Source Code KendangsiterActivity.java

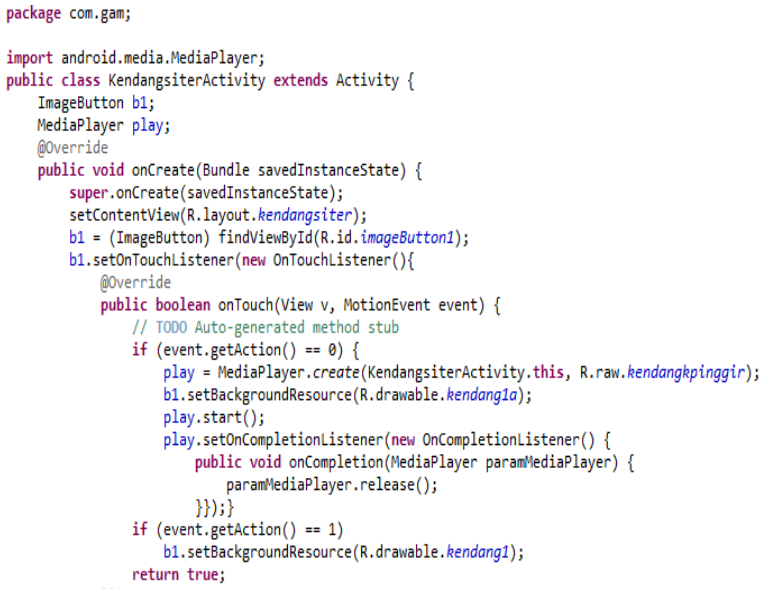

Source Code diatas berisi perintah untuk memutar suara pada tampilan Kendang Siter bagian kecil yang biasa dimainkan di sebelah kiri pada bagian luar. Baris pertama merupakan lokasi package yang berada di com.gam. baris kedua merupakan daftar perintah yang akan di- import. Sedangkan baris 3-5 merupakan daftar kelas yang terdapat pada pemrograman tersebut. Terdapat 5 (lima) kelas yang berada dalam permrograman Kendang Siter tersebut. Baris 6-8 merupakan pernyataan bahwa tampilan yang dipakai adalah layout kendangsiter. Baris 9-20 merupakan perintah ketika user menyentuh gambar, maka file suara pada kendang kecil sebelah luar akan diputar, serta gambar akan berganti menjadi kendangla yaitu modifikasi dari tampilan kendang bagian yang kecil. Dan pada baris 21-24 merupakan perintah untuk mengganti ke gambar kendangl ketika sentuhan dilepaskan.

B. Terakhir merupakan data diri dari penyusun aplikasi adalah sebagai berikut:

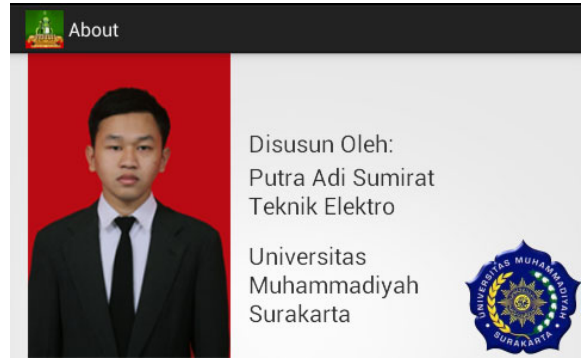

Gambar 10. Tampilan tentang penyusun aplikasi

Analisis program:

a.Source Code about.xml

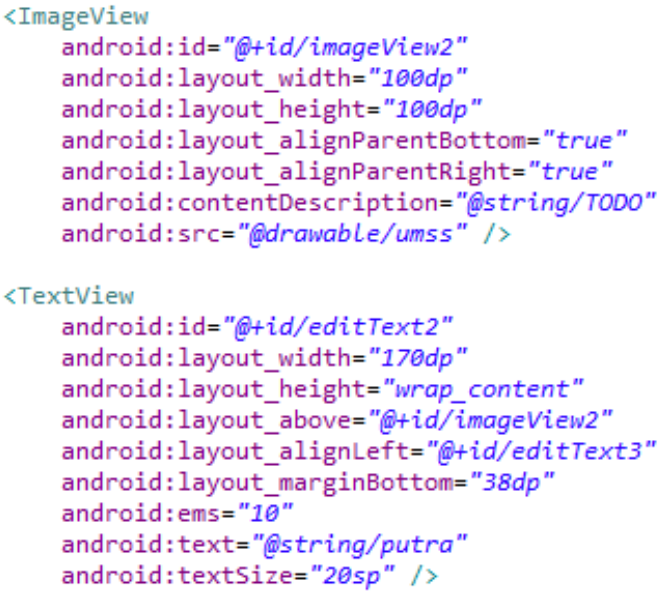

Source code diatas merupakan perintah untuk menampilkan gambar dengan id/imageView2 yang bernama umss dan text dengan id/editText2 yang dipanggil dari values/string dengan nama putra.

\section{b. Source Code AboutActivity.java}

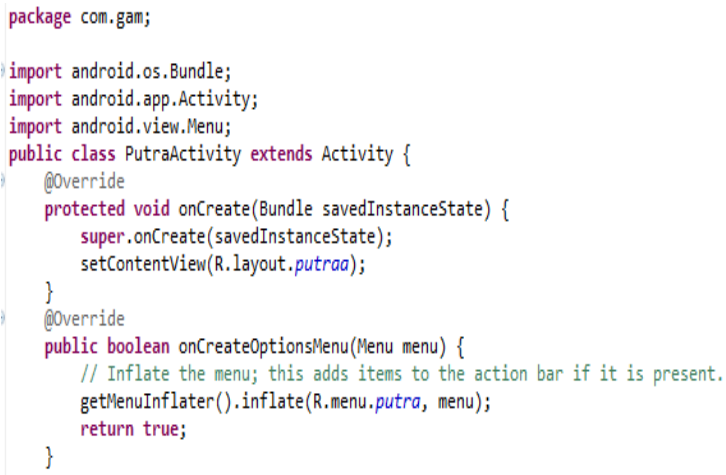


Source Code diatas merupakan perintah untuk menampilkan layout dengan nama putraa.

c. Analisis Kelebihan dan Kelemahan

1. Analisis Kelebihan

Jika pada aplikasi Gamelan Jawa berbasis android yang sudah ada saat menyentuh perangkat gamelan hanya ada warna merah serta suara yang ditimbulkan sangat kecil dan juga untuk smartphone dengan spesifikasi rendah agak lambat, maka saat ini Gamelan yang penulis buat, saat menyentuh notasi Gamelan maka gambar dapat bergetar, dengan suara yang keras serta lebih cepat.

2. Analisis Kelemahan

Kelemahan dari aplikasi Gamelan Jawa berbasis android ini adalah tidak dapat digunakan untuk multiuser.

3. Pembahasan Sistem

Pembuatan aplikasi ini bertujuan agar user dapat memainkan seperangkat Gamelan Jawa dengan praktis dan dapat dimainkan dimana saja. Perangkat Gamelan Jawa berbasis android ini pada bagian bilahnya akan bergetar jika disentuh, serta juga dapat dimainkan dengan dua jari, dan dapat menghasilkan dua nada dalam waktu yang bersamaan. Pada perangkat Gamelan Toetoel berbasis android yang sudah ada, pada saat dicoba pada smatphone penulis dengan spesifikasi yang standar, terasa loading-nya terlalu lama saat menyentuh bilah Gamelan untuk menghasilkan suara, hanya tombol menjadi warna merah transparan, sedangkan perangkat Gamelan yang penulis buat, bilah atau lempengan yang disentuh user dapat bergetar dan suara dapat langsung terdengar tanpa loading yang terlalu lama.

\section{Kesimpulan}

Kesimpulanyangdapatdiambildari karya ilmiah iniadalahsebagaiberikut:

1. Perancangan aplikasi Gamelan Jawa pada perangkat android ini dibuat berdasarkan analisis dari penulis dengan harapan dapat membantu melestarikan kebudayaan dan menjaga identitas bangsa Indonesia.

2. Aplikasi Gamelan Jawa berbasis android ini dapat dijadikan sarana hiburan untuk masyarakat umum dan membantu memperkenalkan kebudayaan pada generasi penerus.
3. Aplikasi ini dibuat dengan berbasis mobile sehingga user dapat memainkan perangkat Gamelan ini dimana saja.

\section{DAFTAR PUSTAKA}

Android Developer, 2013, Media Player http://developer.android.com/reference/a ndroid/media/MediaPlayer.html Diakses 1 Agustus 2013 pukul 13.05.

Google Play, 2012, Gamelan DJ https://play.google.com/store/apps/detail $\underline{\mathrm{s} ? \mathrm{id}=\text { com.KowplinkGDJ.game Diakses }}$ 28 Agustus 2013 pukul 15.15.

Google Play, 2012, Gatoel (Gamelan Toetoel) https://play.google.com/store/apps/detail s?id=com.b201.gatul Diakses 28 Agustus pukul 15.30.

Hariyanto, Bambang, 2007, Esensi-Esensi Bahasa Pemrograman Java. Bandung: Informatika.

Hartanti, Sri, 2007, Pemrograman GUISwing Java Dengan Netbeans 5 v.5. Yogyakarta: Andi.

Haryono, Timbul, 2011, Gamelan Jawa Sejarah dan Perkembangannya. http://clubbing.kapanlagi.com/threads/1 5400-GAMELAN-JAWA-Sejarah-danPerkembangannya. Diakses tanggal 14 April 2013 14.40.

Kinanthi, 2012, Gamelan Jawa. http://nisyacin.blogdetik.com/gamelanjawa/. Diakses tanggal 8 September 2013 pukul 08.30.

Kurniawanto, Andhika, 2011, Belajar Gamelan Jawa Menggunakan Platform iOS. Program Studi Teknologi Multimedia Broadcasting, Politeknik Elektronika Negeri Surabaya, Institut Teknologi Sepuluh Nopember. Surabaya.

Pew, John A, 1997, Instant Java. Yogyakarta: Andi. 
Plengdut, 2012, Sistem Nada. http:/www.plengdut.com/2012/12/siste m-nada.html. Diakses tanggal 14 April 2013 pukul 14.35 .

Pratama, Widianto, 2011, Tutorial Android Programing, Part1: Pengenalan Android. http://www.widiandroid.com/. Diakses tanggal 14 April 2013 pukul 14.40 .

Purnama, Rangsang, 2007, Pemrograman GUI Menggunakan Java. Jakarta: Prestasi Pustakarya.
Sanchez, Julio, 2002, Java Tm 2 Weekend Crash Course Tm. Jakarta: Elex Media Komputindo.

Utomo, Eko Priyo, 2012, From Mewbie To Advanced, Mudahnya Membuat Aplikasi Android. Yogyakarta. Andi.

Wijono, Matius Soesilo, 2007, Java 2 SE Dengan JBuilder. Yogyakarta: Andi.

Yahya, Isa, 2008, Sistem Band Musik Digital Pada Portable PC Berbasiskan Web. Jurusan Teknik Elektro, Sekolah Teknik Elektro Dan Informatika, Institut Teknologi Bandung. Bandung. 